\title{
RELAÇÃO DA PRECIPITAÇÃO PLUVIOMÉTRICA E AÇÃO ANTRÓPICA COM OS DESLIZAMENTOS DE TERRA OCORRIDOS NA ESCARPA DA SERRA DA ESPERANÇA: EVENTO DE 29 DE SETEMBRO DE 2014
}

\author{
Jéssica Borodiak $^{(\text {a) }}$, Claudiane da Costa ${ }^{(b)}$, Aparecido Ribeiro de Andrade ${ }^{(c)}$, Juliane Bereze ${ }^{(\mathrm{d})}$ \\ (a) Acadêmica de Geografia, Universidade Estadual do Centro Oeste - UNICENTRO, jeborodiak@ hotmail.com \\ (b) Programa de Pós Graduação, Universidade Estadual do Centro Oeste - UNICENTRO, \\ clau_dianecosta@hotmail.com \\ ${ }^{(c)}$ Professor Dr da Universidade Estadual do Centro Oeste - UNICENTRO, apaandrade @ gmail.com \\ (d) Mestre em Geografia pela Universidade Estadual do Centro Oeste - UNICENTRO, \\ juliane.bereze@hotmail.com
}

\section{Eixo: CLIMATOLOGIA EM DIFERENTES NÍVEIS ESCALARES: MUDANÇAS E VARIABILIDADES}

\begin{abstract}
Resumo
O objetivo do presente trabalho foi identificar a influência da intensidade da precipitação pluviométrica e da ação antrópica em eventos geomorfológicos (deslizamentos) em uma área com relevo escarpado, conectando o Leste e o Oeste paranaense, denominada localmente de Serra da Esperança. Foi possível entender a dinâmica que ocorreu em um evento no dia 29 de setembro de 2014, no qual o volume de precipitação pluviométrica foi extremo (acima da média e fora do desvio padrão), intensificado pelo fato de que nos dias anteriores já havia ocorrido eventos pluviométricos, superando em poucos dias o total de chuva esperado para o mês inteiro. Portanto, os deslizamentos aconteceram em virtude do solo estar totalmente saturado. Como o deslizamento é um evento repetitivo, o presente trabalho busca chamar a atenção para a falta de planejamento adequado buscando solução para o problema em curto prazo, possibilitando minimizar o risco de ocorrer novos deslizamentos.
\end{abstract}

Palavras chave: Precipitação; ação antrópica; deslizamentos.

\section{Introdução}

A ação antrópica ocorrida através da construção de rodovias e estradas influencia na aceleração de erosões, principalmente por causa dos processos de remoção da vegetação e retilinização do relevo nas vertentes. Além dessa ação, a própria dinâmica natural, representada pela interação das condições climáticas com o tipo de solo e a geologia local, também auxiliam na maior ou menor intensidade dos processos erosivos. A precipitação pluviométrica é considerada o principal agente exógeno nesse processo, mas é atenuada ou intensificada pelas intervenções da sociedade humana. Essa dinâmica pode acarretar deslizamentos e movimentação de massa, fragilizando o solo e vindo a ocorrer catástrofes como o movimento de massas nas vertentes de forma irregular e incontrolável.

Os processos geomorfológicos como os movimentos de massa tem origem natural e são responsáveis pela formas do relevo, modelando as formas e sendo responsáveis pela evolução morfológica das 
vertentes. Esses processos por si só não oferecem riscos ao homem, no entanto, quando áreas que possuem características físicas suscetíveis à movimentação são ocupadas pela população ou sofrem alteração antrópica como a construção de estradas, rodovias e ferrovias, se transformam em áreas de risco. Essas áreas podem ocasionar danos econômicos e acidentes com perdas de vidas.

Para Ross (1990) o relevo terrestre é parte importante do palco onde o homem, como ser social, pratica o teatro da vida. Sendo assim, devido à necessidade de locomoção e de moradia, o homem faz algumas alterações e em alguns casos deixa de levar em consideração as forças endógenas e exógenas,sendo que estas juntas e em oposição, determinam toda a existência e toda a dinâmica do meio biótico e abiótico da superfície terrestre. Através de variações topográficas e morfológicas abrem-se espaço para o aumento da possibilidade de riscos, permitindo então o deslocamento de matéria liquida e sólida das partes mais altas para as mais baixas, em um processo contínuo de desgastes dos terrenos elevados e de acumulação nos segmentos baixos.

No Paraná, a Serra da Esperança é uma área com relevo escarpado, onde foi construída uma Rodovia (BR 277) que é a principal conexão entre o leste e o oeste paranaense. Todos os anos, em períodos chuvosos, o solo tende a ceder, ocorrendo deslizamentos de terra e rocha no local, dificultando ou impedindo totalmente a passagem de veículos. No dia 29 de setembro de 2014 a BR 277estava com uma das pistas interditada, pois a chuva contínua que precipitava sobre Guarapuava e região provocou o deslizamento de uma rocha com lama, a qual ocasionou a interdição. (REDE SUL, 2014).

A área do presente estudo concentra-se entre os municípios de Guarapuava e Prudentópolis, embora a Área de Proteção Ambiental da Serra da Esperança ocupe mais alguns municípios na transição do segundo para o terceiro planalto paranaense ao Sul do Brasil. Os dois municípios tem como caracterização climática preponderante o Clima Subtropical Úmido, com mais de 5 geadas noturnas anualmente e chuvas bem distribuídas. A Serra da Esperança é constituída por estratos de arenito São Bento Inferior ou Botucatu, com espessos derrames de lavas básicas compactadas do Trapp do Paraná (derrame vulcânico de basalto), atingindo para oeste uma altitude de 1.100 a 1.750 metros (MAACK, 2002).

Esta área é bastante ilustrativa para os frequentes deslizamentos que acontecem na região. Além do corte na vertente para a passagem da rodovia, existe uma ampla rede de drenagem que se ramifica de forma dentrítica em todos os sentidos.Vários rios dessa rede influenciaram naconstrução de extensos viadutos. Os indícios de deslizamentos são recorrentes neste local indicando que a ação antrópica pode ter acelerado os processos naturais de erosão. 


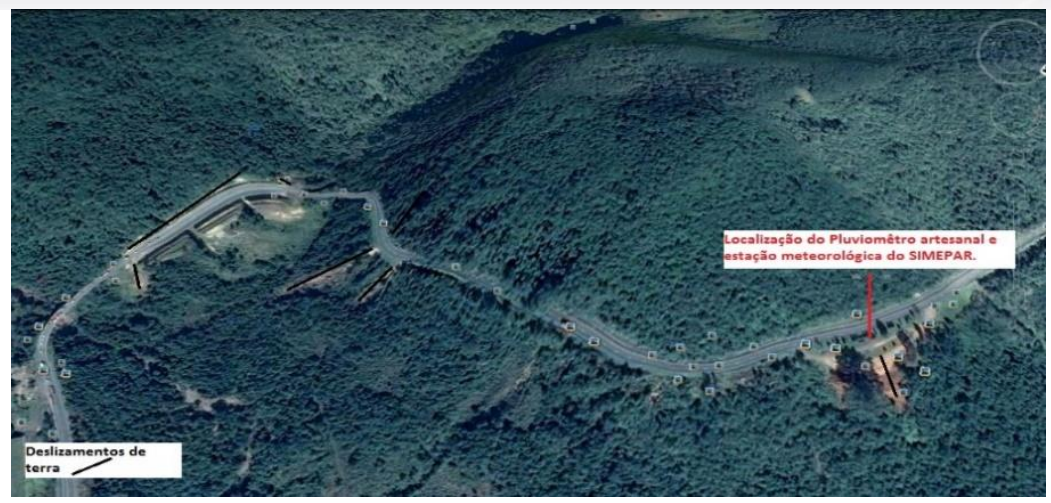

Figura 1: Trecho da Serra Esperança entre Guarapuava e Prudentópolis Fonte: Google Earth, 2014 (adaptada por Costa. C)

\section{Materiais e Métodos}

Para a elaboração deste trabalho foram utilizadas reportagem de um jornal local e observação da área de estudo em saídas de campo. Essas informações qualitativas foram avaliadas juntamente com dados pluviométricos mensais e diários, obtidos nosite do Instituto das Águas Paraná.

A estação pluviométrica de Prudentópolis está em uma altitude de 850 metros e a de Guarapuava a 950 metros. Além destes, também foram utilizados dados de um pluviômetro artesanal de cano de Policloreto de Vinila, (que é um dos tipos de plástico usualmente conhecido como PVC) para áreas remotas, adaptado de Galvani e Lima (2012). Esse pluviômetro foi instalado no local indicado na Figura 2, com altitude de 966 metros. Posteriormente, os dados foram tabulados no software Microsoft Office Excelß. Esse mesmo software também foi utilizadopara a obtenção da média mensal e para elaboração de gráficos. Por fimocorreu a sistematização de todas as informações e dados para obter os resultados presentes neste trabalho.

\section{Resultados e Discussões}

A maioria dos eventos que ocorrem na margem da rodovia tem como material de base transportado o Arenito Botucatu, basalto alterado e blocos de basalto (VIEIRA, 2008). Nesse mesmo local ocorreu o evento do dia 29 de setembro de 2014.

Na Figura 2 observa-se que a média da precipitação para o mês de setembro em Guarapuava é de 174,8mm e para Prudentópolis é de 161,1mm. 


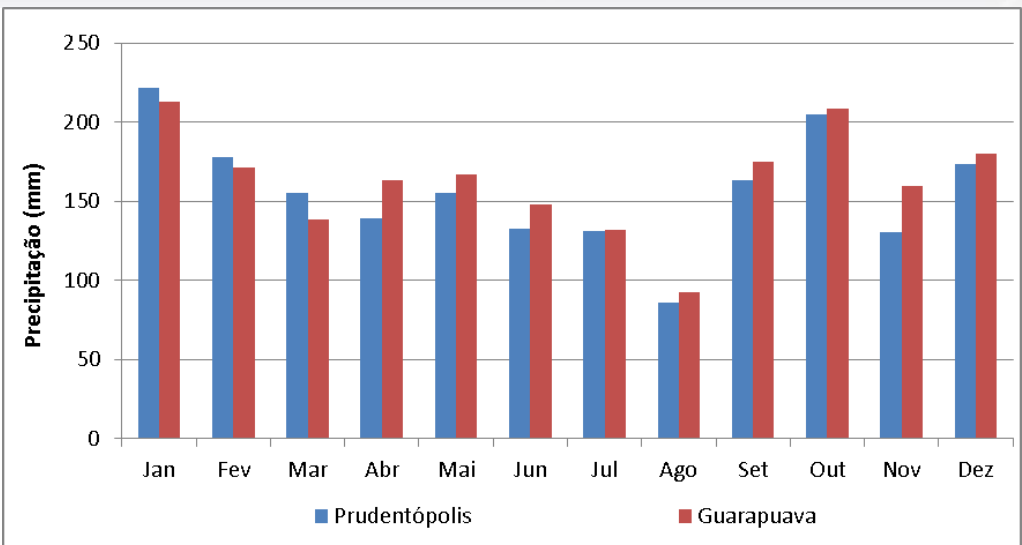

Figura 2: Média Mensal da precipitação das estações de Prudentópolis e Guarapuava1983-2013

Fonte: Instituto das águas Paraná

No mês de setembro do ano de 2014 choveu acima da média esperada, pois no total de precipitação no mês a estação pluviométrica de Prudentópolis registrou 307,3mm e a estação de Guarapuava registrou $348,5 \mathrm{~mm}$, ou seja, praticamente o dobro do esperado.

No dia 29 de setembro, quando aconteceram os deslizamentos de terra na Serra da Esperança, a estação de Guarapuava registrou 99,3mm, sendo que nos dias anteriores já havia um acumulado de 162,3mm. Na estação de Prudentópolis foram registrados 41,0mm e nos dias anteriores teve um acumulado de $84,3 \mathrm{~mm}$. Percebe-se então, que a causa dos deslizamentos não foi somente a chuva do dia, mas o fato de que o solo já estava saturado, em virtude da grande quantidade de chuva que havia precipitado nos dias anteriores (Figura 3).

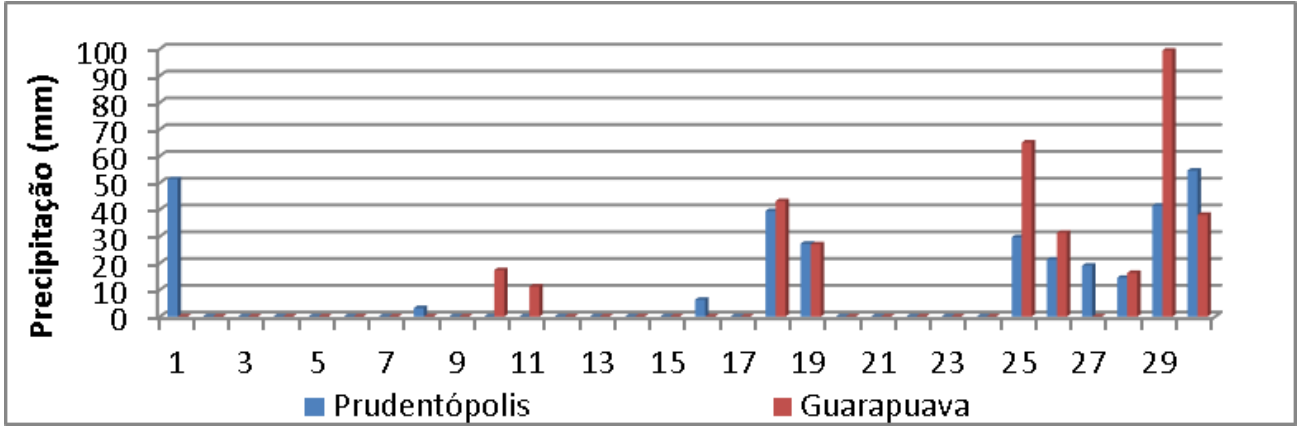

Figura 3: Dados diários para o mês de setembro de 2014 das estações de Prudentópolis e Guarapuava.

Fonte: Instituto das águas Paraná

O pluviômetro artesanal registrou um acúmulo de 280mm no período de 25/09 até 30/09/2014. Observa-se então certa variabilidade espacial na distribuição da chuva, mas todas as estações registraram chuvas intensas (acima de $40 \mathrm{~mm} / \mathrm{dia}$ ). 
Nesse sentido, Tucci (1997), salienta queo total da precipitação não tem significado se não estiver ligado a uma duração.Pode-se ter um mês chuvoso, mas se a chuva for bem distribuída, não implicará, por exemplo, em deslizamentos. Por outro lado,pode ocorrer um mês menos chuvoso, mas se a chuva ficar concentrada em poucos dias, pode ocasionar deslizamentos pela saturação do solo. No caso do deslizamento do dia 29/09/2014 na Serra da Esperança, os dois fatores influenciaram (tanto o acúmulo da chuva quanto o tempo de duração).

\section{Conclusão}

Nota-se que a quantidade e intensidade da chuva associada às modificações antrópicas ocorridas na morfometria da vertentecausaram os deslizamentos. Em um pequeno espaço de tempo (quatro a cinco dias) ocorreram sucessivos deslizamentos e movimentação de massa. Este é um processo catastrófico ampliado pela intensidade da chuva, e ainda mais pelas intervenções antrópicas, alterando a hidrologia de vertente. Isto causa um desequilíbrio no processo natural de erosão das vertentes. O mesmo processo que possibilita melhor acesso entre áreas diferentes também causa interrupção nessa via e pode causar prejuízos incalculáveis para os municípios da região e o estado do Paraná como um todo.

As técnicas em hidrogeomorfologia apresentam algumas alternativas que podem ser utilizadas no local para amenização dos problemas, como muro de contenção,suavização do talude, grelha protegida de concreto armado, construção de canaletaspara contenção de taludes. No local em que ocorreram os deslizamentos do dia 29 existe um pequeno muro com tela, mas este não consegue conter toda a lama com rochas que deslizam nos eventos mencionados. A rodovia que passa neste local é objeto de concessão, razão pela qual não se sabe se há projetos que possam minimizar estes problemas.

\section{Referências}

GALVANI, E; LIMA, N G B1 ${ }^{\text {a }}$ Ed (2012) Climatologia aplicada: resgate aos estudos de caso. Curitiba.

INSTITUTO das águas do Paraná: Sistema de Informações Hidrológicas. Disponível em:http://www.aguasparana.pr.gov.br/(Acessado em 15 de março de 2016)

MAACK, R; $3^{a}$ ed (2002) Geografia Física do Estado do Paraná. Imprensa Oficial; Curitiba.

REDE Sul de Notícias (2014) BR 277 na Serra da Esperança está com uma pista interditada. Disponível em: http://www.redesuldenoticias.com.br/home.asp?id=73023 (acessado em 15 de março de 2016)

REDE Sul de Notícias (2014) Chuva causa desmoronamento na Serra da Esperança. Disponível em: http://www.redesuldenoticias.com.br/home.asp?id=36190(Acessado em 10 de abril de 2016)

ROSS, J L S; coleção repensando geografia (1990) Geomorfologia: ambiente e planejamento. São Paulo, Brasil

TUCCI, C E M; $2^{\text {a }}$ ed (1997) Hidrologia: ciência e aplicação. Editora Universidade. Porto Alegre. 
VIEIRA, S F (2008)Análise e mapeamento das áreas suscetíveis a movimentos de massa no setor central da serra da esperança, na divisa entre os municípios de Guarapuava e Prudentópolis- PR. Dissertação de Mestrado. Universidade Federal de Santa Catarina (UFSC) Santa Catarina. 